\title{
FLEXIBILIDADE E DESENVOLVIMENTO TÉCNICO NA GINÁSTICA OLÍMPICA
}

Nestor Soares Publio ${ }^{\star \star}$

RESUMO

Os objetivos dêste trabalho foram o de investigar a flexibilidade durante um treinamento de ginástica olímpica, comparar os resultados obtidos entre ginastas mirins, estudantis, nacionais e internacionais, e comparar a média das notas das seis provas (solo, ca-

\section{INTRODUÇÃO}

A ginástica olímpica está em constante desenvolvimento, desafiando e obrigando os especialistas a modificarem os seus conceitos e métodos de treinamento.

Entre as mais importantes capacidades físicas para o desenvolvimento técnico da ginástica olimpica, resolveu-se investigar a importância da flexibilidade.

Orientando sôbre a preparaçāo física do ginasta, Magakian (1966) afirma que se deve trabaIhar em primeiro lugar a flexibilidade.

Segundo Ukran (1978) os ginastas em geral possuem elasticidade perfeita, todavia alguns não podem alcançar bons resultados devido a mobilidade insuficiente das articulaçōes. Hadjiew (1981) comenta que a insuficiência de flexibilidade nas articulações dos quadris e dos ombros principalmente impede uma boa execução em diversos exercícios. Para Friedrich e Nilson (1981) para se considerar o indice do deslocamento escápulo- valo com arçōes, argolas, salto sôbre o cavalo, paralela e barra fixa) e da barra fixa isoladamente com os resultados obtidos com quatro testes especificos desta capacidade física.

umeral como ideal, a execução deve ser realizada com os braços paralelos e estendidos.

Fetz e Kornexl (1976), apresentam alguns testes de mobilidade articular semelhantes aos citados por Harre (1973) para controle e avaliação da mobilidade de ginástica olímpica.

\section{DESENVOLVIMENTO}

A população examinada consistiu em setenta e sete ginastas do sexo masculino, subdivididos em quatro grupos: $G-1$, nove mirins, com média de 10 anos; $\mathrm{G}-2$, quarenta e oito estudantis, com média de 15,8 anos; G-3, treze nacionais, com média de 20,5 anos e G-4, sete internacionais, com média de 21,6 anos.

Todos os ginastas dos grupos, 1, 2, 3 e 4, foram submetidos a uma bateria composta de quatro testes específicos de flexibilidade para ginástica olímpica: a) Flexão do tronco para frente

Resenha da Dissertaçāo de Mestrado apresentada à EEFUSP em 1983.

** Professor Assistente da disciplina de Ginástica Olimpica da EEFUSP 
na posição em pé; b) Flexão do tronco para frente na posição sentada; c) Espacato ântero-posterior e d) Deslocamento escápulo-umeral.

O G-1, participou de um estudo desenvolvido durante setente e cinco dias, com treinamento de cento e vinte minutos, cinco vezes por semana. Os testes foram aplicados em todos os participantes do G-1, no início e no final do treinamento, para análise da evolução de cada variável.

Após os resultados do G-1, resolveu-se avaliar com os mesmos testes ginastas estudantis (participantes dos Jogos Escolares Brasileiros JEBs de 1978 a 1983); ginastas nacionais (participantes do Torneio Nacional de 1982) e ginastas internacionais (integrantes da seleção soviética, campeã mundial e olímpica de 1980 e 1981, por ocasião das demonstraçōes realizadas no Ginásio do Ibirapuera em 1981), para comparação dos resultados entre os quatro grupos.

Aproveitando os resultados dos Jogos Escolares Brasileiros, comparou-se a média dos pontos das seis provas de ginástica olímpica com os resultados dos exercícios de flexibilidade dois a dois em virtude de terem sido as flexōes do tronco medidas em centímetros e por outro lado terem sido corrigidos os dados referentes ao espacato ântero-posterior e deslocamento escápulo-umeral, para maior homogeneidade dos resultados.

Da mesma forma, aproveitando os resultados do Torneio Nacional, comparou-se a nota da barra fixa com os resultados dos exercícios de flexibilidade, observando-se o mesmo critério.

Para a análise da evolução de cada variável no G-1, foi utilizado o teste " $T$ " de Student para amostras correlacionadas. (Tabela 1)
Para a comparação dos resultados dos testes de flexibilidade entre os quatro grupos (Tabela 2) foi utilizada uma Análise de Variância a um fator nāo métrico.

Para comparar a média dos pontos das seis provas de ginástica olímpica dos JEBs com os exercícios de flexibilidade, aplicou-se a Análise de Regressão Linear, para verificar quais as variáveis independentés que mais afetaram a média dos ginastas.

Para comparar a nota de barra fixa do Torneio Nacional com os exercícios de flexibilidade, aplicou-se também a Análise de Regressão Linear, para verificar quais as variáveis independentes que mais afetaram a nota do ginasta na barra fixa.

$O$ nível de significância utilizado em todos os testes foi de 0,05 .

\section{CONCLUSÕES}

Os resultados obtidos no treinamento dos ginastas mirins, nas avaliações dos ginastas estudantis, nacionais e internacionais e nas pontuaçōes dos Jogos Escolares Brasileiros e Torneio Nacional, tornaram possíveis as seguintes conclusōes:

1 A flexibilidade melhorou de maneira significativa no treinamento de ginástica olimpica em meninos com idade média de dez anos.

2 O confronto dos resultados dos quatro testes, nos quatro grupos mostrou a diferença significativa nos exercícios de flexão do tronco.

Tabela 1 Valores médios, desvios padrōes e evolução da bateria de testes de flexibilidade a que foi submetido o Grupo Mirim no pré e pós-testes.

\begin{tabular}{|c|c|c|c|c|}
\hline & $\begin{array}{l}\text { Flexão do Tronco } \\
\text { para Frente na } \\
\text { Posição em Pé }\end{array}$ & $\begin{array}{l}\text { Flexão do Tronco } \\
\text { para Frente na } \\
\text { Posição Sentada }\end{array}$ & $\begin{array}{c}\text { Espacato } \\
\text { Ântero- } \\
\text { posterior }\end{array}$ & $\begin{array}{c}\text { Deslocamento } \\
\text { Escápulo- } \\
\text { umeral }\end{array}$ \\
\hline $\begin{array}{r}\text { PRÉ-TESTE } \bar{X} \\
S\end{array}$ & $\begin{array}{r}11,33 \\
3,35\end{array}$ & $\begin{array}{r}13,00 \\
2,83\end{array}$ & $\begin{array}{l}1,10 \\
0,03\end{array}$ & $\begin{array}{l}1,74 \\
0,20\end{array}$ \\
\hline $\begin{array}{r}\text { PÓS-TESTE } \bar{X} \\
S\end{array}$ & $\begin{array}{r}15,78 \\
2,39\end{array}$ & $\begin{array}{r}15,56 \\
3,21\end{array}$ & $\begin{array}{l}1,18 \\
0,02\end{array}$ & $\begin{array}{l}1,57 \\
0,22\end{array}$ \\
\hline $\begin{array}{ll}\text { EVOLUÇÃO } & \overline{\mathrm{d}} \\
\mathrm{s}_{\mathrm{d}}\end{array}$ & $\begin{array}{l}4,40 \\
1,94\end{array}$ & $\begin{array}{l}2,60 \\
1,33\end{array}$ & $\begin{array}{l}0,09 \\
0,04\end{array}$ & $\begin{array}{l}0,17 \\
0,14\end{array}$ \\
\hline $\mathrm{t}$ & $6,80^{+}$ & $5,86+$ & $6,45^{+}$ & $-3,69+$ \\
\hline
\end{tabular}

$+P 0,05$ 
Tabela 2 Valores médios e desvios padrōes da bateria de testes de flexibilidade no Grupo Mirim, Estudantil, Primeira Categoria e Internacional.

\begin{tabular}{|c|c|c|c|c|}
\hline & $\begin{array}{c}\text { Flexāo do Tronco } \\
\text { para Frente na } \\
\text { Posição em Pé }\end{array}$ & $\begin{array}{l}\text { Flexão do Tronco } \\
\text { para Frente na } \\
\text { Posição Sentada }\end{array}$ & $\begin{array}{l}\text { Espacato } \\
\text { Ântero- } \\
\text { posterior }\end{array}$ & $\begin{array}{c}\text { Deslocamento } \\
\text { Escápulo- } \\
\text { umeral }\end{array}$ \\
\hline $\begin{array}{r}\mathrm{G}-1 \\
\overline{\mathrm{X}} \\
\mathrm{S}\end{array}$ & $\begin{array}{r}15,78 \\
2,39\end{array}$ & $\begin{array}{r}15,56 \\
3,21\end{array}$ & $\begin{array}{l}1,18 \\
0,02\end{array}$ & $\begin{array}{l}1,57 \\
0,22\end{array}$ \\
\hline $\begin{array}{r}G-2 \\
\bar{X} \\
S\end{array}$ & $\begin{array}{r}19,50 \\
4,51\end{array}$ & $\begin{array}{r}20,93 \\
4,57\end{array}$ & $\begin{array}{l}1,10 \\
0,08\end{array}$ & $\begin{array}{l}1,38 \\
0,33\end{array}$ \\
\hline $\begin{array}{r}G-3 \\
\bar{X} \\
S\end{array}$ & $\begin{array}{r}23,31 \\
5,39\end{array}$ & $\begin{array}{r}23,69 \\
4,57\end{array}$ & $\begin{array}{l}1,15 \\
0,03\end{array}$ & $\begin{array}{l}1,55 \\
0,41\end{array}$ \\
\hline $\begin{array}{r}G-4 \\
\bar{X} \\
S\end{array}$ & $\begin{array}{r}21,00 \\
6,58\end{array}$ & $\begin{array}{r}22,00 \\
8,00\end{array}$ & $\begin{array}{l}1,14 \\
0,05\end{array}$ & $\begin{array}{l}1,38 \\
0,53\end{array}$ \\
\hline
\end{tabular}

3 - A média das notas das seis provas de ginástica olímpica foi influenciada significativamente mais pela flexão do tronco para frente na posiçāo sentada do que na posiçāo em pé.

4 A média das notas das seis provas de ginástica olímpica foi influenciada significativamente mais pelo espacato ântero-posterior do que pelo deslocamento escápulo-umeral.
5 A nota de barra fixa na ginástica olímpica foi influenciada significativamente mais pela flexão do tronco para frente na posiçāo sentada do que na posiçāo em pé.

6 A nota de barra fixa na ginástica olímpica foi influenciada significativamente mais pelo deslocamento escápulo-umeral do que pelo espacato ântero-posterior.

\section{ABSTRACT}

The aims of this work were to investigate flexibility during an olympic gymnastic training, to compare the results gottens by gymnasts of different levels and to compare the six events average grades (floor exerci- se, pommel horse, rings, vaulting, parallel bars and horizontal bar) and the horizontal bar separatily with the results gotten by four specific tests of this physical capability. 